\title{
A Comparative Evaluation of the Treatment of Hyperthyroidism
}

\author{
KuniHiko ITO, Yoshiniko NISHIKAWA, TANEKaZU HARADA, \\ TAKUYA SUZUKI, NAOKo MOMOTANI, NOBUHIRO MARUCHI* \\ AND TAKEHIKO TSUCHIYA** \\ Ito Hospital, Tokyo 150, Department of Health Administration, \\ Tokyo University School of Health Sciences, Tokyo 113* and \\ Division of Radiation Hazards, National Institute of \\ Radiological Sciences, Chiba 280**
}

\begin{abstract}
Synopsis
In order to evaluate the effect of treatment for hyperthyroidism based on a proposed criteria from our institution, the patients with the disease first seen at the Ito Hosiptal during 1965 were studied on the basis of clinical diagnosis and the follow-up study in 4-5 year period.

Surgery was recommeded in the younger ages and radioiodotherapy in the higher ages for both sexes, though there was no inclination for antithyroid therapy in ages. Surgery exihibited the most reliable result among the three major therapies. Hypothyroidism was found more often in females than in males. Incidence of hypothyroidism with radioiodotherapy after the first four years of therapy was about $10 \%$ in females, and the result indicated the necessity of further improvement for administering ${ }^{131} \mathbf{I}$. In case of radioiodotherapy, it is difficult to predict the manifestation of hypothyroidism, because of no relationship between the incidence of hypothyroidism and radiation dose. The follow-up study showed the remission rates with surgery and radioiodotherapy were both $80-90$ per cent, whereas the rate with antithyroid therapy was 38 per cent.
\end{abstract}

After the introduction of radioiodotherapy or antithyroid therapy for hyperthyroidism, the principle of the treatment of the disease has shown so remarkable modification. Among the major therapies for the disease, such as ${ }^{131} \mathrm{I}$ (radioiodotherapy), subtotal thyroidectomy or antithyroid drugs (ATD), each therapy has certain advantages, as well as disadvantages, as compared with each other.

The evaluation for each therapy, however, has so many differences or discrepancies among the specialists. Since no treatment of the disease is completely satisfactory and its etiology is not known, it is not surprising that several types of therapy have been tried.

Surgery had been the only method of treatment for hyperthyroidism at the Ito Hospital unitl 1955, when radioiodine ${ }^{131} \mathrm{I}$

Received for publication January 8, 1974. also became available for treatment. ATD have been applied since 1947. Prior to 1963, however, they were administered in preparation to surgery and not as independent treatment. Since then we have applied all three kinds of treatment based on our criteria for indication. Our criteria for the choice of treatment with the disease were established in 1956 and have not yet been modified.

In order to examine the clinical situation for the choice of treatment with the disease, all new patients with the disease seen in 1965 at the Ito Hospital were studied in this paper.

\section{Materials and Methods}

\section{Patients}

The 1,124 cases with hyperthyroidism were first seen at the hospital in 1965 . Of these cases, 177 were 
Table 1. Distribution of the patients with hyperthyroidism, by sex and age-group

\begin{tabular}{ccccccccc}
\hline \hline Sex & -19 & $20-$ & $30-$ & $40-$ & $50-$ & $60-$ & Total \\
\hline $\begin{array}{c}\text { Male } \\
(\%)\end{array}$ & $(4.5)$ & $(24.9)$ & $(38.4)$ & $(24.9)$ & $(6.7)$ & $(0.6)$ & $(100.0)$ \\
Female & 129 & 233 & 281 & 192 & 93 & 19 & 947 \\
$(\%)$ & $(13.6)$ & $(24.6)$ & $(29.7)$ & $(20.3)$ & $(9.9)$ & $(2.0)$ & $(100.0)$ \\
\hline
\end{tabular}

male and 947 were female. The youngest was 9 years of age and the oldest was 76 years years old (Table 1).

The 496 cases (44.1 per cent of 1,124 cases) had no history of previous treatment for the disease, whereas the remainders (628 cases) had some kind of previous treatment for the disease elsewhere prior to visiting our clinic.

Out of the 1,124 patients, one of the three major treatments was tried in 1,066 cases. 930 cases $(87.2$ per cent of the 1,066 cases) were treated in the hospital, and the others were recommended to transfer to other hospitals or quit their regular visit.

\section{Diagnosis and grading}

The diagnosis of hyperthyroidism was made by a medical history, physical examination, and an abnormal value of two or more of the following tests; basal metabolic rate, resine-sponge uptake, protein bound iodine, and 24-hour thyroidal ${ }^{131}$ I uptake.

An impression was recorded as to one of three degrees of severity of hyperthyroidism based on all data available, using the designation mild, moderate, or severe. The size and configuration was traced and recorded as large, medium, or small (estimated weight over $50 \mathrm{~g}, 20-49 \mathrm{~g}$, or less than $20 \mathrm{~g}$ respectively). All cases composed of diffuse toxic goiter; toxic nodular goiter was not seen in the series.

\section{Selection of treatment}

Our criteria on the choice of treatment for hyper- thyroidism was shown in Table 2 . Relations between the status of patient and the kind of treatment were as follow:

a) History of previous treatment

Among the 628 previously treated cases, 563 were treated with ATD administration, 26 with ${ }^{131} \mathrm{I}$ administration, and 39 with surgery.

b) Recommendation of treatment by age

Figure 1 shows the distribution of patients for each treatment by age-group. ATD treatment was given to most of age-groups, ranging from 11 to 33 per cent. Under the age-group of 30-39, the majority of cases were recommended for surgery, and patients over 40 were mostly recommended for ${ }^{131} \mathrm{I}$ administration.

c) Size of thyroid enlargement by treatment

Surgery was more performed for the patients with large goiter as well as medium size of goiter, whereas ATD was mainly performed for small size of thyroid enlargement. This was shown in Table 3.

d) Severity of hyperthyroid status by treatment

Figure 2 shows the relation between severity of hyperthyroidism and their selected treatment. ATD treatment was performed mainly for mild cases. ${ }^{131} \mathrm{I}$ administration was, on the other hand, performed mainly for most severe cases. Surgery was mainly performed for the moderate cases.

e) Duration of hyperthyroid status by treatment

Duration of the disease in each group of three treatments was shown in Table 4. About half of the patients less than 3 years duration of the disease

Table 2. Criteria for the selection of the treatment for hyperthyroidism

\begin{tabular}{|c|c|c|c|}
\hline Subject & ATD & ${ }^{131} \mathrm{I}$ & Surgery \\
\hline Age & any age & middle and over & younger age \\
\hline Size of goiter & small & medium or small & large or medium \\
\hline $\begin{array}{l}\text { Severity of hyper- } \\
\text { thyroidism }\end{array}$ & mild & severe or modrate & severe or moderate \\
\hline Duration of illness & short duration & long duration & no consideration \\
\hline $\begin{array}{l}\text { Marital status and } \\
\text { pregnancy }\end{array}$ & no consideration & post reproductive age & younger age \\
\hline Social factors & $\begin{array}{l}\text { accessibility to regular } \\
\text { medical care }\end{array}$ & no consideration & early return to job \\
\hline Complications & no consideration & no consideration & to avoid \\
\hline
\end{tabular}




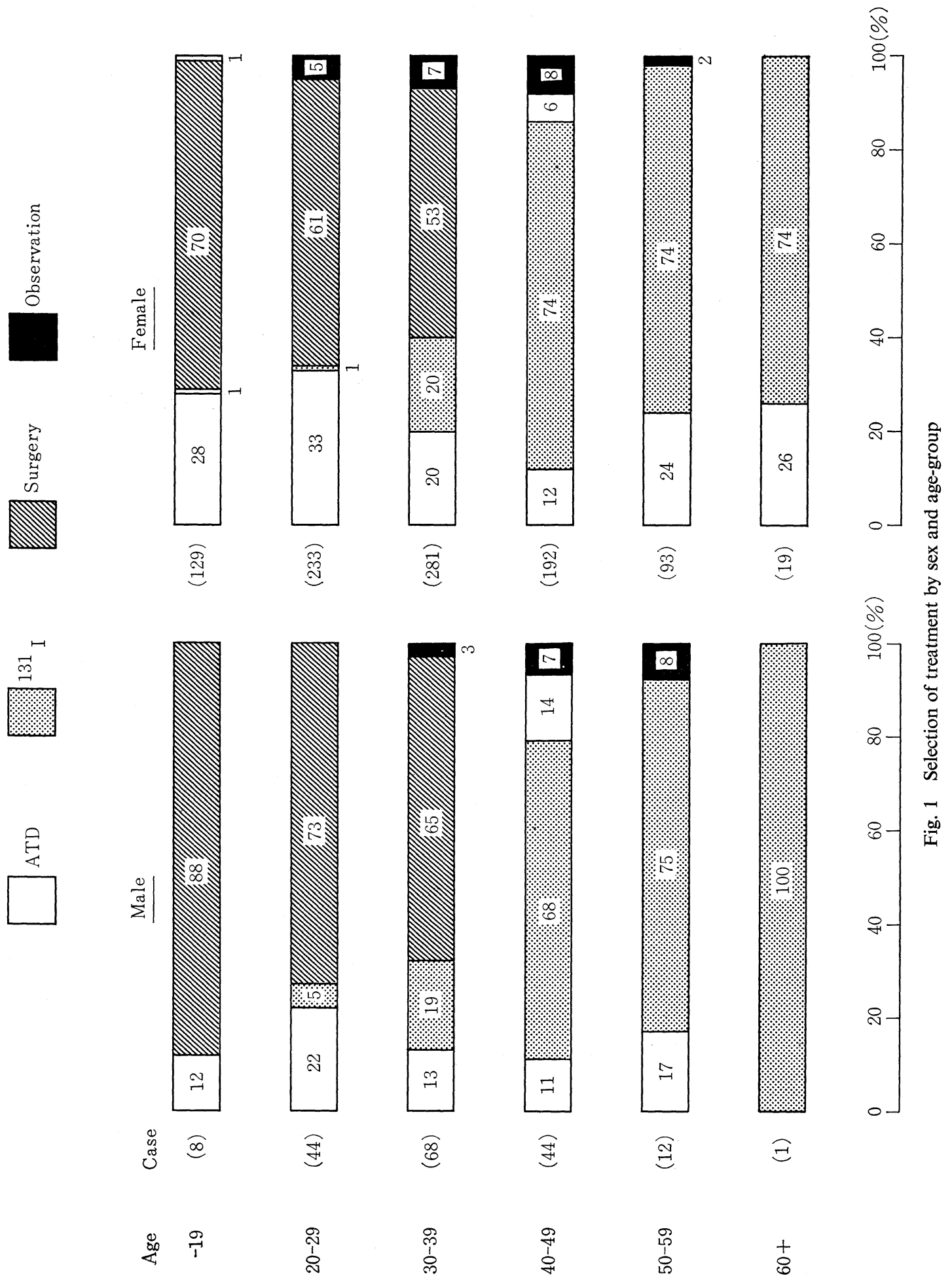


Table 3. Size of thyroid enlargement

\begin{tabular}{lrrrrr}
\hline Size & ATD & ${ }^{131}$ I & Surgery & Observation & Total \\
\hline Large & $12(6)$ & $39(18)$ & $163(75)$ & $4(2)$ & $218(100)$ \\
Medium & $85(15)$ & $189(33)$ & $293(51)$ & $10(2)$ & $577(100)$ \\
Small & $138(48)$ & $105(36)$ & $24(8)$ & $24(8)$ & $291(100)$ \\
No detail & $12(32)$ & $5(13)$ & $1(3)$ & $20(53)$ & $38(100)$ \\
Total & $247(22)$ & $338(30)$ & $481(43)$ & $58(5)$ & $1,124(100)$ \\
\hline
\end{tabular}

\section{( ); percentage}

Severity Case

Severe

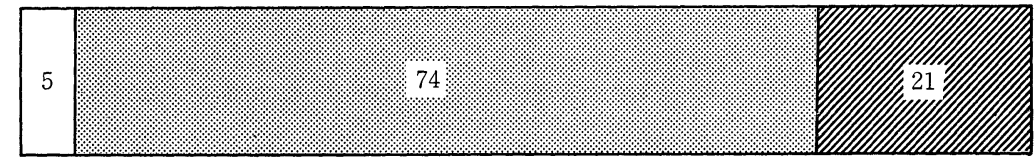

Moderate

(900)

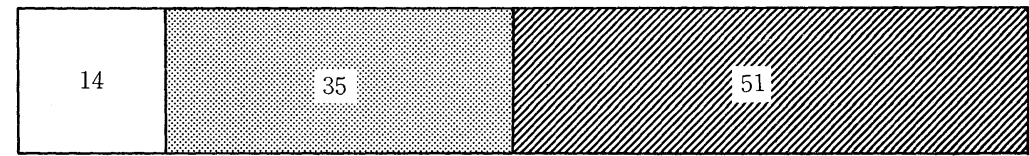

Mild

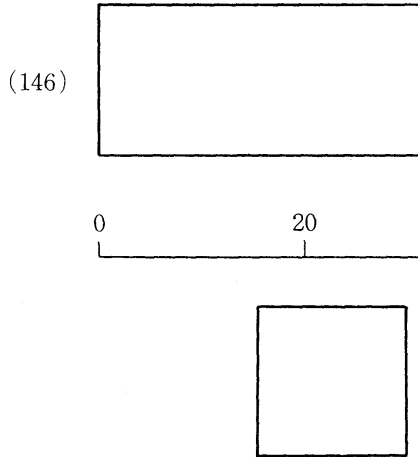

ATD
82

40

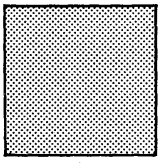

${ }^{131}$
13

80

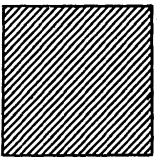

Surgery

Fig. 2 Relation of severity to the selection of treatment

Table 4. Duration of hyperthyroidism

\begin{tabular}{lccccc}
\hline Duration & ATD & ${ }^{131}$ I & Surgery & Observation & Total \\
\hline Less than 1 year & $156(22)$ & $206(29)$ & $332(46)$ & $21(3)$ & $715(100)$ \\
1 year to less than 3 years & $50(20)$ & $73(30)$ & $109(44)$ & $15(6)$ & $247(100)$ \\
3 years and over & $40(25)$ & $58(37)$ & $39(25)$ & $21(13)$ & $158(100)$ \\
No detail & 1 & 1 & 1 & 1 & $4(100)$ \\
Total & $247(22)$ & $338(30)$ & $481(43)$ & $58(5)$ & $1,124(100)$ \\
\hline
\end{tabular}

( ); percentage 
Table 5. Performance of treatment, by sex

\begin{tabular}{|c|c|c|c|c|c|c|}
\hline \multirow{2}{*}{$\begin{array}{l}\text { Indication } \\
\text { Performence }\end{array}$} & \multicolumn{3}{|c|}{ Male } & \multicolumn{2}{|c|}{ Female } & \multirow[b]{2}{*}{ Surgery } \\
\hline & ATD & ${ }^{131} \mathrm{I}$ & Surgery & ATD & ${ }^{131} \mathrm{I}$ & \\
\hline ATD & $\begin{array}{r}25 \\
(89)\end{array}$ & 0 & 0 & $\begin{array}{l}188 \\
(86)\end{array}$ & $\begin{array}{r}2 \\
(1)\end{array}$ & $\begin{array}{c}5 \\
\text { (1) }\end{array}$ \\
\hline${ }^{131} \mathbf{I}$ & 0 & $\begin{array}{r}49 \\
(91)\end{array}$ & 0 & 0 & $\begin{array}{l}269 \\
(95)\end{array}$ & $\begin{array}{c}3 \\
\text { (1) }\end{array}$ \\
\hline Surgery & 0 & 0 & $\begin{array}{r}80 \\
(90)\end{array}$ & 0 & $\begin{array}{r}1 \\
(0)\end{array}$ & $\begin{array}{l}308 \\
(79)\end{array}$ \\
\hline No teatment & $\begin{array}{r}3 \\
(11)\end{array}$ & $\begin{array}{r}5 \\
(9)\end{array}$ & $\begin{array}{r}9 \\
(10)\end{array}$ & $\begin{array}{c}31 \\
(14)\end{array}$ & $\begin{array}{l}12 \\
(4)\end{array}$ & $\begin{array}{r}76 \\
(19)\end{array}$ \\
\hline Total & $\begin{array}{r}28 \\
(100)\end{array}$ & $\begin{array}{r}54 \\
(100)\end{array}$ & $\begin{array}{r}89 \\
(100)\end{array}$ & $\begin{array}{r}219 \\
(100)\end{array}$ & $\begin{array}{r}284 \\
(100)\end{array}$ & $\begin{array}{r}392 \\
(100)\end{array}$ \\
\hline
\end{tabular}

( ); percentage

were treated with surgery. Patients more than 3 years duration of the disease were predominantly treated with ${ }^{131}$ I treatment.

\section{f) Complicated disorders}

Although there were patients with complication of cardiovascular disorders (44 cases), hypertension ( 238 cases), diabetes mellitus (13 cases), and periodic paralysis (36 cases), no consideration was actually taken for the selection of treatment. In the case of patients with psychiatric disorders ( 21 cases), treatment was chosen after the consultation with psychiatrists.

\section{Relation between indication and actual treatment}

The relation of recommended treatment to performance of the treatment for hyperthyroidism are shown in Table 5. Although about 90 per cent of male patients with the disease were equally treated in each mode, female patients showed a stronger inclination against surgery. The reasons were as follows; of 8 cases in which treatment other than surgery were done, five were treated with ATD administration because of refusal for surgery ( 3 cases) and of well responded to preoperative ATD administration ( 2 cases). The other three patients were treated with ${ }^{131} \mathrm{I}$ administration because of anemia in one case and depression in the remaining two.

\section{Method of treatment}

a) Antithyroid drugs (ATD)

The cases for this indication were principally treated with methimazole, but some cases were treated with propylthiouracil because of the side effect with methimazole. The initial dose of methimazole was 15 to $30 \mathrm{mg}$, three times daily, then reduced gradually as the thyroid function tests showed the normal range until the minimum maintenance dose of $5 \mathrm{mg}$ daily was obtained. Maintenance dose was continued for at least one year. In the case of propylthiouracil treatment, the initial dose was 300 $\mathrm{mg}$ in three divided doses daily, and maintenance dose of 50-100 mg daily. The majority of cases were treated on outpatient basis and allowed with their daily activity. Those patients not responding with ATD administration were requested to have one of other treatments in its early stage.

b) Radioiodine $\left({ }^{131} I\right)$

${ }^{131} \mathrm{I}$ was administered orally in a single dose aiming to deliver 6,000 to 8,000 rads to the thyroid. The method of calculating the amount of ${ }^{131}$ I to be given was followed by Mc Gavacks formula (1951).

$$
\begin{aligned}
& \text { Radiation dose }(\text { Rads })=0.2 \times 93.7 \\
& \times \frac{{ }^{131} \text { I uptake } 24 \mathrm{hr}(\%) \times \text { effective half life (day) }}{\text { Weight of gland }(\mathrm{g})} \\
& \times \text { administration dose }(\mathrm{mc})
\end{aligned}
$$

Uptake and effective half life were counted and calculated by a preliminary tracer dose administration. The weight of thyroid gland was assessed by Okubo's formula (1959) which was established on the basis of practical comparison between surgically resected specimen of the hyperthyroid goiter and its scintigram. After the administration of therapeutic dose actual radiation dose delivered to the thyroid was also counted and calculated for confirmation. If the estimated dose of ${ }^{131} \mathrm{I}$ was not to be delivered to the gland, deficient amount of ${ }^{131} \mathrm{I}$ was added immediately. In such instance, while ${ }^{131} \mathrm{I}$ was given twice, number of doses was regarded as a single dose. The cases failed to reach euthyroid status with the above treatment were classified as post-therapic hyperthyroid status in the result of follow-up study. ${ }^{131}$ I treatment was not recommeded for unmarried women and women with future possibility of pregnancy. Those beyond their reproductive age were 
Table 6. The Follow-up results of ATD treatment

A. Patients maintaining euthyroid less than 1 year after cessation of medication

.84 cases

$\begin{array}{cc}\text { 1. Administration continued } & 33 \text { cases } \\ \text { 2. Treatment altered } & 35 \text { cases } \\ \text { to iodine- } 131 & 20 \text { cases } \\ \text { to surgery } & 15 \text { cases } \\ \text { 3. Under observation } & 16 \text { cases }\end{array}$

B. Patients maintaining euthyroid over 1 year after cessation of medication .51 cases
1. Over 1 year-less than 2 years
16 cases
2. Less than 3 years
16 cases
3. Less than 4 years
12 cases
4. Over 4 years
7 cases

C. Others

1. Treatment discontinued

78 cases

2. Transferred to other hospitals 34 cases

usually treated with ${ }^{131} \mathrm{I}$ administration.

c) Surgery

Patients undergoing surgery were prepared by the administration of ATD until euthyroidism was obtained. Lugol solution was given only when the patients had an extremely large goiter or had side effects with ATD administration. The detail of surgical procedure was previously reported by the authors (1969). All cases with surgery were operated only by the first author. Surgery was selected for patients who needed to return to their work as early as possible. The same was true for patients living in remote area, without access to satisfactory medical care.

\section{Follow-up}

The follow-up study of the 930 cases treated in the hospital was carried out from July 1969 through June 1970. The patients were requested to visit outpatient clinic for the evaluation of their thyroid function. Thyroid status was evaluated by two function tests, generally resine-sponge up-take and protein bounding iodine as well as physical examination. In a few cases, evaluation was made by questionaire sent to patients, or by evaluation of the nearby practicing physicians. The follow-up data was obtained in 685 cases (73.3 per cent of the 930 cases), including 9 dead cases. All deaths were not related to hyperthyroidism, except one case with unknown cause.

On the other hand, another questionnaire was sent to the patients with hyperthyroidism to whom surgery were carried out in our series to ask their judgement of the surgical scar.

\section{Results}

\section{a) ATD Treatment}

The results of ATD administration is sum- marized in Table 6. Of 135 followed-up cases, patients achieved remission lasting more than one year was only in 37.5 per cent.

\section{b) ${ }^{131}$ I Treatment}

The results of this treatment revealed that 80.5 per cent (186 cases of 231 followed-up cases) obtained euthyroidism by 4 to 5 years after single dose administration (Table 7). This remission rate was significantly better than that of ATD treatment. It is noteworthy that the remission rate in male was excellent with 90.9 percent with no development of hypothyroidism, whereas in female the rate was not as favorable with 78.8 per cent of euthyroidism and 10.6 per cent of hypothyroidism. Hyperthyroidism persisted in 9.1 per cent of male and 10.6 per cent of female

Table 8 shows the relationship between the actually delivered radiation dose to the thyroid and the thyroid status at the follow-

Table 7. Follow-up status with patients treated with ${ }^{131} \mathrm{I}$, by sex

\begin{tabular}{lrrrr}
\hline \multirow{2}{*}{ Sex } & \multicolumn{3}{c}{ Thyroid Function } & \\
\cline { 2 - 4 } & $\begin{array}{l}\text { Hyper- } \\
\text { thyroid }\end{array}$ & $\begin{array}{c}\text { Eu- } \\
\text { thyroid }\end{array}$ & $\begin{array}{c}\text { Hypo- } \\
\text { thyroid }\end{array}$ & \\
\hline Male (\%) & $3(9)$ & $30(91)$ & 0 & $33(100)$ \\
Female (\%) & $21(11)$ & $156(79)$ & $21(11)$ & $198(100)$ \\
Total $(\%)$ & $24(10)$ & $186(81)$ & $21(9)$ & $231(100)$ \\
\hline
\end{tabular}

( ); percentage 
Table 8. Relationship of radiation dose to the thyroid function at the follow-up status in female patients

\begin{tabular}{|c|c|c|c|c|}
\hline \multirow{2}{*}{$\begin{array}{l}\text { Radiation } \\
\text { Dose }\end{array}$} & \multicolumn{3}{|c|}{ Thyroid Function } & \multirow[b]{2}{*}{ Total } \\
\hline & $\begin{array}{l}\text { Hyper- } \\
\text { thyroid }\end{array}$ & $\underset{\text { Eu- }}{\text { Euroid }}$ & $\begin{array}{l}\text { Hypo- } \\
\text { thyroid }\end{array}$ & \\
\hline $\begin{array}{l}-5000 \\
\text { rads }\end{array}$ & 1 & 1 & 1 & $3(100)$ \\
\hline $\begin{array}{l}5001-6000 \\
\text { rads }\end{array}$ & 0 & $4(67)$ & $2(23)$ & $6(100)$ \\
\hline $\begin{array}{l}6001-7000 \\
\text { rads }\end{array}$ & $2(17)$ & $10(83)$ & 0 & $12(100)$ \\
\hline $\begin{array}{l}7001-8000 \\
\text { rads }\end{array}$ & $3(9)$ & $26(76)$ & $5(15)$ & $34(100)$ \\
\hline $\begin{array}{l}8001-9000 \\
\text { rads }\end{array}$ & $2(5)$ & $32(87)$ & $3(8)$ & $37(100)$ \\
\hline $9001+$ rads & $4(6)$ & $58(83)$ & $8(11)$ & $70(100)$ \\
\hline No detail & $9(25)$ & 25(69) & $2(6)$ & $36(100)$ \\
\hline Total & $21(11)$ & $156(79)$ & $21(11)$ & $198(100)$ \\
\hline
\end{tabular}

( ); percentage

up in female cases. It seemed that radiation sensitivity of thyroid gland was quite different from case to case. In some cases, hyperthyroidism persisted among patients irradiated with a large radiation dose and in others hypothyroidism resulted despite a small dose of irradiation delivered. Mode of radiation dose delivered to those obtained euthyroidism was 8,640 rads $(4,940-17,520$ rads), those with persistent hyperthyroidism, 8,000 rads $(4,800-13,400$ rads) and those developed hypothyroidism, 8,250 rads $(3,080$ 11,020 rads). Thus, no relation could be found between the incidence rate of hypothyroidism and radiation dose.

\section{c) Surgery}

Table 9 summarizes the result of surgical treatment in 295 follow-up cases; 75.8 per cent of the 389 cases operated on. Euthyroid was obtained in 93.9 per cent among them. This remission rate was significantly better than that for ATD or ${ }^{131}$ I treatments. The surgical records were reviewed in regard to the twelve hyperthyroid patients relapsed or persistent; seven cases were presumed due to the large amount of thyroid tissue left behind
Table 9. Follow-up status with patients after surgery, by sex

\begin{tabular}{|c|c|c|c|c|}
\hline \multirow[b]{2}{*}{ Sex } & \multicolumn{3}{|c|}{ Thyroid Function } & \multirow[b]{2}{*}{ Total } \\
\hline & $\begin{array}{l}\text { Hyper- } \\
\text { thyroid }\end{array}$ & $\begin{array}{c}\mathrm{Eu}- \\
\text { thyroid }\end{array}$ & $\begin{array}{l}\text { Hypo- } \\
\text { thyroid }\end{array}$ & \\
\hline Male & $5(8)$ & $56(90)$ & $1(2)$ & $62(100)$ \\
\hline Female & $7(3)$ & $221(95)$ & $5(2)$ & $233(100)$ \\
\hline Total & $12(4)$ & $277(94)$ & $6(2)$ & $295(100)$ \\
\hline
\end{tabular}

and the reasons for the remaining cases were unknown. In the case of hypothyroid patients, it was proved that the remnant of thyroid tissue was too small and histologically lymphoid infiltration was demonstrated in all cases.

In regard to complications of surgery, there were 10 cases of transient tetany and 4 cases of transient unilateral vocal cord paralysis among 389 operated cases. No surgical mortality and postoperative thyroid storm took place.

In term of a questionnaire sent to the patients to whom surgery were carried out for asking their judgement of the surgical scar, answers were obtained in 202 cases among 389 operated cases. The results were as follows; hardly noticeable 29 (14\%), slightly noticeable $132(20 \%)$, and extremely evident $8(4 \%)$.

\section{Discussion}

Among the three major treatment for hyperthyroidism, namely ATD, ${ }^{131} \mathrm{I}$, and subtotal thyroidectomy, the last one was the only treatment for this disease in the past. Administration of iodine provided transient control of the disease and reduction of vascularity of the gland. Astwood (1943), however, introduced the thiourea in the treatment of hyperthyroidism; but high recurrence rates and frequent toxic reaction made the antithyroid drug unsatisfactory for definitive therapy. About the same time, ${ }^{131}$ I became 
available for treatment of this disease. Radioiodotherapy appeared ideal due to lack of operative risks, good control of symptoms, and although other methods of treatment revealed drawbacks, this form of treatment was accepted predominantly. Later, however, follow-up studies disclosed radioactive iodine treatment resulted in high incidence of posttherapeutic hypothyroidism.

In ATD treatment, the term of medication is generally so long that it is not so easy to achieve the completion of the therapy as physician expects. Some patients discontinue the medication by their judgement and others would continue incomplete medication. The remission rate of ATD administration in our study was lower than the following reports; Solomon et al., (1953) 45\%, McCullagh and Cassidy (1953) $66 \%$, Trotter (1961) $45 \%$, Reveno and Rosenbaum (1964) $57 \%$, Hershman et al., (1966) $54 \%$, and Shizume (1969) $49 \%$. In regard to our low remission rate, it might be argued that the selection of cases or method of administration was not appropriate: Mild cases with smaller goiter and shorter duration of illness were more likely treated with ATD as was shown in Figure 2 and Table 3. As to the administration of ATD, methimazole was administered ranging from 15 to $30 \mathrm{mg}$ three times daily as the initial dose, and in most cases $20 \mathrm{mg}$. This dose seems to be small compared with the above other reports. Recently we have found to increase our initial dose to $30 \mathrm{mg}$ or more daily. Furthermore, cases which failed to respond quickly to ATD or presented difficulty of maintaining euthyroidism by administration of the maintenance dose, were switched to other mode of therapy at an earlier stage.

Solomon et al., (1953), Reveno and Rosenbaum (1964), and Shizume (1969) emphasized that the smaller goiter responds more favorably to ATD administration than the larger one. It was, however, difficult to show in our result since cases with larger goiter were not treated with ATD in our series. As Hershman et al., (1966) and
Shizume (1969) stated, there was a tendency that remission was more often obtained in cases with goiter which diminished in size during the period of treatment.

The high incidence of hypothyroidism developed after ${ }^{131}$ I treatment has been in debate. Segal et al., (1961) reported $17.9 \%$ of hypothyroid among the followed-up cases after 5 years of ${ }^{131} \mathrm{I}$ administration, Green and Wilson (1964) $18.8 \%$ after 5 years, and Zellmann et al., (1968) $20.6 \%$ after 4 years. However, the incidence of hypothyroidism reported in Japan seems to be relatively lower than Occidental ones; Shizume reported 5.1\% of hypothyroidism among the followed-up cases after 4 years of ${ }^{131} \mathrm{I}$ administration, and Hara and Kitabatake $9.9 \%$ after 5 years. In our series, $9.1 \%$ of hypothyroidism was confirmed among the followed-up cases after 4 to 5 years of ${ }^{131} \mathrm{I}$ administration. The difference in frequency between Japanese and Occidental reports may derived from the difference of radiation dose and/or racial sensitivity to ${ }^{131} \mathrm{I}$.

Among the three major treatment of hyperthyroidism in our study, the remission rate of surgical treatment was most satisfactory as stated in the results. Maruta et al., (1966), Noguchi and Noguchi (1967), Kuma and Kuma (1963), and Ezaki et al., (1968) of Japan also reported similar results as ours. However, the authors of those reports with excellent results were believed to be experienced in thyroid surgery. It is the fact that the results are not always satisfactory unless surgery is performed by experienced thyroid surgeons.

Since scar formation is inevitable and the majority of patients with hyperthyroidism are young women, the appearance of scar constitutes an important problem for them.

From the cosmetic point of view, the result of the inquiry on the patients to whom surgery were carried out revealed that about two thirds of the cases were not much concerned with the scar. 


\section{References}

Astwood, E. B. (1943). J.A.M.A. 122, 78.

Ezaki, H., T. Shigemitsu, H. Funaoka, M. Araki, T. Sasao and S. Kato (1968). Geka Rinsho 19, 52. (In Japanese).

Green, M. and G. M. Wilson (1964). Brit. Med. J. 1, 1005.

Hara, M. and T. Kitabatake (1973). Clin. Radio. (Rinsho Hohshasen) 18, 527 (In Japanese).

Hershman, J. M., J. R. Givens and C. E. Cassidy (1966). J. Clin. Endocrinol. 26, 803.

Ito, K., Y. Nishikawa and T. Harada (1969). Geka (Surgery) 31, 1039 (In Japanese).

Kuma, S. and R. Kuma (1963). J.P.S.S. (Nihon Rinsho Geka Igakkai Zasshi) 24, 305 (In Japanese).

Maruta, K., R. Furihata, H. Shida, H. Nakafuji, Y. Ishida, T. Sato, S. Nomura, T. Miyazaki, B. Terajima, A. Muramatsu, A. Adachi, S. Ikeda, S. Miyakawa, M. Yonekura and Y. Koike (1966). J.J.S.S. (Nihon Geka Gakkai Zasshi) 76, 1464 (In
Japanese).

McCullagh, E. P. and C. E. Cassidy (1953). J. Clin. Endocrinol. 13, 1507.

McGavack, T. H. The Thyroid. C. V. Mosby, St. Louis, p. 193 (1951).

Noguchi, A. and S. Noguchi (1967). Saishin Geka 22, 1535 (In Japanese).

Okubo, T. (1959). Act. Radiol. 19, 120 (In Japanese).

Reveno, W. S. and H. Rosenbaum (1964). Ann. Int. Med. 60, 982.

Segal, R. L., S. Silver, S. Yohalem and S. Feitelberg (1961). Amer. J. Med. 31, 354.

Shizume, K. (1965). Naika 16, 1277 (in Japanese).

Shizume, K. (1969). Nihon Ishikai Zasshi 62, 435 (In Japanese).

Solomon, D. H., J. G. Beck, W. P. Vanderlaan and E. B. Astwood (1953). J.A.M.A. 152, 201.

Trotter, W. R. (1961). Proc. of Roy. Soc. of Med. 54, 869.

Zellmann, H. E., H. Matiz, E. C. Bartels and G. O. Bell (1968). Lahey Clin. Found. Bull. 17, 137. 